\title{
Mitomycin C Induces Apoptosis in Rheumatoid Arthritis Fibroblast-Like Synoviocytes via a Mitochondrial-Mediated Pathway
}

\author{
Chuqi Yana Dechao Kong ${ }^{b}$ Dong Ge ${ }^{c}$ Yanming Zhang ${ }^{d}$ Xishan Zhang ${ }^{d}$ \\ Changhui Su ${ }^{d}$ Xiaojian $\mathrm{Cao}^{\mathrm{a}}$
}

\begin{abstract}
aDepartment of Orthopedics, The First Affiliated Hospital of Nanjing Medical University, Nanjing, ${ }^{b}$ Department of Orthopedics, The First People's Hospital Affiliated to Shanghai Jiao Tong University, Shanghai, 'Department of Orthopedics, The Central Hospital of Taian, Taian, dDepartment of Orthopedics, The Affiliated Hospital of Taishan Medical College, Taian, China
\end{abstract}

\section{Key Words}

Mitomycin C $・$ Rheumatoid arthritis • Fibroblast-like synoviocytes $•$ Apoptosis $•$ Mitochondrial pathway

\begin{abstract}
Background/Aims: Rheumatoid arthritis (RA) is a systemic chronic inflammatory disease characterised by prominent synoviocyte hyperplasia and a potential imbalance between the growth and death of fibroblast-like synoviocytes (FLS). Mitomycin C (MMC) has previously been demonstrated to inhibit fibroblast proliferation and to induce fibroblast apoptosis. However, the effects of MMC on the proliferation and apoptosis of human RA FLS and the potential mechanisms underlying its effects remain unknown. Methods: Cell viability was determined using the Cell Counting Kit-8 assay. Apoptotic cell death was analysed via Annexin V-FITC/ PI double staining and terminal deoxynucleotidyl transferase-mediated dUTP-biotin nickend labelling. The production of intracellular reactive oxygen species (ROS) was assessed via flow cytometry, and the changes in mitochondrial membrane potential $\left(\Delta \Psi_{\mathrm{m}}\right)$ were visualised based on JC-1 staining via fluorescence microscopy. The expression of apoptosis-related proteins was determined via Western blot. Results: Treatment with MMC significantly reduced cell viability and induced apoptosis in RA FLS. Furthermore, MMC exposure was found to stimulate the production of ROS and to disrupt the $\Delta \Psi_{\mathrm{m}}$ compared to the control treatment. Moreover, MMC increased the release of mitochondrial cytochrome $\mathrm{c}$, the ratio of $\mathrm{Bax} / \mathrm{BCl}-2$, the activation of caspase- 9 and caspase- 3 , and the subsequent cleavage of poly(ADP-ribose) polymerase. Conclusion: Our findings suggest that $\mathrm{MMC}$ inhibits cell proliferation and induces apoptosis in RA FLS, and the mechanism underlying this MMC-induced apoptosis may involve a mitochondrial signalling pathway.

Copyright (C) 2015 S. Karger AG, Basel

C. Yan and D. Kong contributed equally to this work
\end{abstract}

Prof. Dr. Xiaojian Cao, and Changhui Su

KARGER 125
Department of Orthopedics, The First Affiliated Hospital of Nanjing Medical University, 300 Guangzhou Road, Nanjing 210029 (China)

Tel. +86-013002505801, Fax +86-25-83724440, E-Mail xiaojiancao001@163.com 


\section{Introduction}

Rheumatoid arthritis (RA) is a chronic systemic autoimmune inflammatory disease characterised by the proliferation and invasion of synovial tissues, leading to progressive joint destruction, deformation and, ultimately, physical disability [1,2]. Approximately $1 \%$ of the global population is affected by RA [3]. Although the precise pathogenesis of RA remains unclear, accumulating evidence suggests that fibroblast-like synoviocytes (FLS) play major roles in both the initiation and the progression of RA [4]. FLS, which are physiologically located in the synovial intimal lining, abnormally proliferate and exhibit aggressive, tumourlike behaviour in patients with RA. These cells produce not only proteases that digest cartilage and bone but also cytokines that mediate inflammatory processes [5, 6]. Moreover, RA FLS exhibit resistance to apoptosis induced by various apoptotic stimuli, further facilitating the hyperplastic growth of FLS and the destruction of articular cartilage [7-9]. Therefore, inhibiting the proliferation of RA FLS and inducing apoptosis of FLS are increasingly under consideration as therapeutic approaches for the treatment of RA.

Mitomycin C (MMC), which is an antitumour antibiotic isolated from the fermented filtrate of Streptomyces caespitosus, has widely been used for the treatment of various cancers [10]. Recently, multiple studies have shown that MMC inhibits fibroblast proliferation and induces fibroblast apoptosis $[11,12]$. Moreover, our previous studies have demonstrated that topical MMC application may inhibit cell proliferation and induce apoptosis in epidural scar fibroblasts, thereby preventing peridural adhesion after laminectomy [13, 14]. However, whether MMC inhibits human RA FLS proliferation or induces the apoptosis of these cells has yet to be reported.

Apoptosis is a highly regulated process of programmed cell death that is crucial for the maintenance of homeostasis [15]. Apoptosis is initiated by either the death receptormediated pathway or the mitochondrial-mediated pathway [16]. A variety of free radicals, such as reactive oxygen species (ROS), are known to cause mitochondrial damage and dysfunction, resulting in the disruption of the mitochondrial membrane potential $(\Delta \Psi \mathrm{m})$ and an increase in the release of cytochrome c from the mitochondria into the cytosol, both of which are regulated by $\mathrm{Bcl}-2$ family proteins. The release of cytochrome c leads to the activation of caspases, thereby inducing apoptosis [17-20].

The aim of the present study was to investigate the effect of MMC on the apoptosis of human RA FLS and the intracellular signalling pathway involved in MMC-induced apoptosis. We examined the effects of different durations of MMC exposure $(50 \mu \mathrm{g} / \mathrm{ml})$ on the following processes: (1) apoptosis of RA FLS, (2) ROS production, and (3) the involvement of the mitochondrial-mediated pathway in MMC-induced apoptosis.

\section{Materials and Methods}

\section{Reagents}

MMC was purchased from Kyowa Hakko Co., Ltd (Tokyo, Japan). Foetal bovine serum (FBS), Dulbecco's modified Eagle's medium (DMEM), trypsin-EDTA, penicillin and streptomycin were purchased from Gibco (Grand Island, NY, USA). A Cell-Counting Kit-8 and the Annexin V-FITC Apoptosis Detection Kit were obtained from Dojindo Laboratories (Kumamoto, Japan). A terminal deoxynucleotidyl transferasemediated dUTP-biotin nick-end labelling (TUNEL) assay kit, 2',7'-dichorofluoresceine diacetate (DCFH-DA), and a 5,5',6,6'-tetrachloro-1,1',3,3'-tetraethyl-benzimidazolcarbocyanine iodide (JC-1) detection kit were obtained from Roche (Mannheim, Germany), Beyotime Institute of Biotechnology (Shanghai, China), and BD Pharmingen (San Diego, CA), respectively. Primary antibodies against Bax, Bcl-2, caspase-9, caspase-3, poly(ADP-ribose) polymerase (PARP), COX-IV, $\beta$-actin, a horseradish peroxidase-conjugated anti-rabbit secondary antibody and enhanced chemiluminescence (ECL) detection substrate were purchased from Cell Signaling Technology (Danvers, MA, USA). The antibody against cytochrome c was purchased from Santa Cruz Biotechnology (Santa Cruz, CA, USA). Unless otherwise specified, all chemicals were purchased from Sigma-Aldrich. 
Yan et al.: Mitomycin C Induces Apoptosis in Rheumatoid Arthritis Fibroblast-Like Synoviocytes

\section{Isolation and culture of FLS}

Synovial tissues from patients with RA were obtained at the time of synovectomy or total knee replacement surgery. All patients fulfilled the American College of Rheumatology criteria for the diagnosis of RA [21]. Informed consent was obtained from each patient, and the procedure was approved by the Ethical Committee of Taishan Medical College. Additionally, all of the studies were performed in compliance with the provisions of the Declaration of Helsinki. Briefly, synovial tissues were minced into small pieces and treated with $2 \mathrm{mg} / \mathrm{ml}$ collagenase type I (Sigma) at $37^{\circ} \mathrm{C}$ for $4 \mathrm{~h}$. After digestion, the tissue suspension was filtered through a 70- $\mu \mathrm{m}$ nylon filter and centrifuged at $400 \times \mathrm{g}$ for $10 \mathrm{~min}$. Then the isolated synovial cells were cultured in DMEM supplemented with 10\% FBS, 100 units $/ \mathrm{ml}$ penicillin, and $100 \mu \mathrm{g} / \mathrm{ml}$ streptomycin at $37^{\circ} \mathrm{C}$ in a humidified atmosphere containing $5 \% \mathrm{CO}_{2}$, and the medium was replaced every three days. FLS from passages three to six were used for all experiments.

\section{Assay of cell viability}

Cell viability was assessed using the Cell Counting Kit-8 (CCK-8) assay. Briefly, the cells were seeded in 96-well plates at a final density of $5 \times 10^{3}$ cells per well in $100 \mu \mathrm{L}$ of medium. After treatment with increasing concentrations $(0,10,25,50$, or $100 \mu \mathrm{g} / \mathrm{ml})$ of MMC for $6,12,24$, and $48 \mathrm{~h}, 10 \mu \mathrm{L}$ of CCK8 solution was added to each well, and the cells were incubated for another $3 \mathrm{~h}$ at $37^{\circ} \mathrm{C}$. Then, the optical density was measured using an absorbance microplate reader (BioTek, Elx800, USA) at a wavelength of 450 $\mathrm{nm}$. This experiment was performed in triplicate. Cell viability was calculated according to the following formula: optical density of the experimental group/optical density of the control group $\times 100 \%$.

\section{Determination of apoptosis via flow cytometry}

Apoptosis of FLS was measured using Annexin V-FITC/PI double staining and was analysed via flow cytometry. Briefly, the cells were seeded at a density of $1 \times 10^{5}$ cells/well in 6-well plates. After exposure to $50 \mu \mathrm{g} / \mathrm{ml} \mathrm{MMC}$ for different durations $(6,12,24$, or $48 \mathrm{~h})$, the cells were harvested with trypsin, washed twice with phosphate-buffered saline (PBS), and resuspended in binding buffer at a concentration of $1 \times$ $10^{6}$ cells $/ \mathrm{ml}$. Then, $100 \mu \mathrm{L}$ of the cell suspension was incubated in $5 \mu \mathrm{L}$ of Annexin V-FITC and $5 \mu \mathrm{L}$ of PI for $15 \mathrm{~min}$ at room temperature in the dark. At the end of the incubation, $400 \mu \mathrm{L}$ of binding buffer was added to the solution. Apoptotic cells were detected using a FACSCalibur flow cytometer (BD Biosciences, San Jose, CA, USA).

\section{TUNEL assay}

The TUNEL assay was also performed to assess apoptosis in this study. Apoptotic DNA fragmentation was detected using an In Situ Cell Death Kit according to the manufacturer's instructions. Briefly, after treatment with MMC, the cells were fixed with $4 \%$ paraformaldehyde for $1 \mathrm{~h}$ at room temperature. After washing with PBS, the cells were permeabilised with $0.1 \%$ Triton X-100 and $0.1 \%$ sodium citrate for 2 min on ice. Next, the cells were incubated in the TUNEL reaction mixture for another hour at $37^{\circ} \mathrm{C}$ in a humidified chamber shielded from light. Then, the cells were stained with DAPI (Roche, Germany) for 5 min. The incidence of apoptosis was examined under a fluorescence microscope (Nikon, Tokyo, Japan). TUNEL-positive cells were considered to be apoptotic, and DAPI-stained cells were counted to determine the total number of cells in a given field of view.

\section{Measurement of intracellular ROS production}

The production of intracellular ROS was detected using the specific fluorogenic probe DCFH-DA. This probe diffuses across the cell membrane and is hydrolysed to $\mathrm{DCFH}$, which is rapidly oxidised to the highly fluorescent compound 2', 7'-dichlorofluorescein (DCF) in the presence of ROS [22]. The DCF fluorescence intensity is proportional to the ROS levels. Because the generation of ROS is an upstream event that occurs during the process of apoptosis [23], the ROS levels were evaluated at early time points. Briefly, after treatment with $50 \mu \mathrm{g} / \mathrm{ml}$ MMC for $1,3,6,12$, or $24 \mathrm{~h}$, the cells were collected and incubated in serum-free DMEM containing $10 \mu \mathrm{M}$ DCFH-DA for $20 \mathrm{~min}$ at $37^{\circ} \mathrm{C}$ in the dark. Then, the cells were washed three times with serum-free DMEM and resuspended in PBS. The intensity of DCF fluorescence was measured via flow cytometry. The relative intensity of DCF fluorescence was expressed as the percentage of the control group. 
Yan et al.: Mitomycin C Induces Apoptosis in Rheumatoid Arthritis Fibroblast-Like Synoviocytes

Measurement of mitochondrial membrane potential $(\Delta \Psi \mathrm{\Psi})$

The $\Delta \Psi \mathrm{m}$ is an important indicator of mitochondrial function, and disruption of the $\Delta \Psi \mathrm{m}$ is suggestive of apoptosis. Loss of $\Delta \Psi \mathrm{m}$ was estimated using a Mitochondrial Membrane Potential Detection Kit that included JC-1. In healthy cells with high membrane potentials, JC-1 spontaneously forms aggregates in the mitochondrial matrix and emits red fluorescence. In apoptotic cells with low $\Delta \Psi \mathrm{m}, \mathrm{JC}-1$ exists as a monomeric form in the cytoplasm, emitting green fluorescence. The change in fluorescence from red to

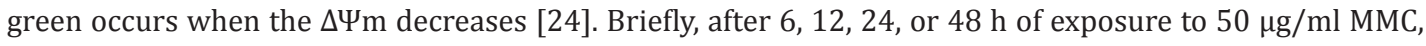
RA FLS were rinsed twice with PBS and incubated at $37^{\circ} \mathrm{C}$ and $5 \% \mathrm{CO}_{2}$ in a JC- 1 working solution for $15 \mathrm{~min}$. The cells were immediately observed under a fluorescence microscope.

\section{Isolation of mitochondrial and cytosolic fractions}

The mitochondrial and cytosolic fractions were isolated from RA FLS using a Mitochondria Isolation Kit for Cultured Cells (Thermo Scientific, USA) as described previously [25]. In brief, the cells were incubated in Mitochondria Isolation Reagent A on ice for $2 \mathrm{~min}$ and then homogenised using a Dounce homogeniser. Following the addition of Mitochondria Isolation Reagent $\mathrm{C}$, the homogenates were centrifuged at $700 \times \mathrm{g}$ for $10 \mathrm{~min}$ at $4^{\circ} \mathrm{C}$. Then, the supernatant was collected and centrifuged at $12,000 \times \mathrm{g}$ for another $15 \mathrm{~min}$ at $4^{\circ} \mathrm{C}$. The cytosolic and mitochondrial fractions were collected separately for further experiments.

\section{Western blot analysis}

Cellular lysates were prepared as described previously [26, 27]. Proteins were resolved using SDSPAGE and transferred to polyvinylidene difloride (PVDF) membranes. Then, the membranes were blocked with 5\% skim milk in Tris-buffered saline containing 0.1\% Tween-20 (TBST) for $1 \mathrm{~h}$ at room temperature and then incubated over-night at $4^{\circ} \mathrm{C}$ in antibodies against Bax, Bcl-2, caspase-9, caspase-3, PARP, $\beta$-actin or COXIV (diluted to 1:1000); or an anti-cytochrome c antibody (diluted to 1:500). After three washes with TBST, the membranes were incubated in a horseradish peroxidase-conjugated anti-rabbit secondary antibody at a dilution of 1:2000 for $1 \mathrm{~h}$ at room temperature. After washing with TBST, the protein bands were visualised using ECL reagents, and images were acquired using a ChemiDoc Imaging system (ChemiDoc ${ }^{\mathrm{TM}} \mathrm{XRS}+\mathrm{System}$ with Image Lab ${ }^{\text {TM }}$ Software; Bio-Rad). The intensities of the protein bands were quantified using Image Lab Software.

\section{Statistical analysis}

All of the data were expressed as the means \pm standard deviation (SD) of triplicate experiments. Statistical analysis was performed using GraphPad Prism 5.01. The significances of the differences between the means were assessed via one-way analysis of variance (ANOVA) followed by Student-Newman-Keuls post-hoc test. P-values of less than 0.05 were considered to be statistically significant.

\section{Results}

\section{MMC decreases cell viability in RA FLS}

To investigate the effect of MMC on RA FLS, we evaluated cell viability using the CCK8 assay following exposure of the cells to various MMC concentrations $(0,10,25,50$, or 100 $\mu \mathrm{g} / \mathrm{ml})$ for different durations $(6,12,24$, or $48 \mathrm{~h})$. As shown in Figure 1, MMC significantly reduced the viability of FLS in a dose- and time-dependent manner. Treatment of these cells with $50 \mu \mathrm{g} / \mathrm{ml} \mathrm{MMC}$ for $24 \mathrm{~h}$ led to a nearly $50 \%$ decrease in cell viability. Hence, $50 \mu \mathrm{g} / \mathrm{ml}$ MMC was used in subsequent experiments.

\section{$M M C$ induces apoptosis in RA FLS}

To quantitatively examine the effect of MMC on apoptosis in FLS, Annexin V-FITC/PI double staining was measured via flow cytometry. Following treatment with MMC (50 $\mu \mathrm{g} /$ $\mathrm{ml}$ for $6,12,24$, or $48 \mathrm{~h}$ ), the percentage of apoptotic cells (including early and late apoptotic cells) was found to gradually increase $(7.74 \% \pm 1.00 \%, 16.34 \% \pm 2.86 \%, 40.50 \% \pm 4.63 \%$ and $73.90 \% \pm 4.74 \%$, respectively) compared with the control treatment $(5.65 \% \pm 0.77 \%)$ (Fig. 2). To further determine the apoptotic effect of MMC on FLS, TUNEL staining was performed. As shown in Figure 3, few TUNEL-positive cells were detected following the 
Yan et al.: Mitomycin C Induces Apoptosis in Rheumatoid Arthritis Fibroblast-Like Synoviocytes

Fig. 1. MMC reduces the viability of human RA FLS. After treatment with increasing concentrations of MMC for $6,12,24$, and $48 \mathrm{~h}$, the effect of MMC on cell viability was determined using the CCK-8 assay. The data represent the means $\pm \mathrm{SD}$ of three independent experiments. ${ }^{*} \mathrm{p}<0.05,{ }^{* *} \mathrm{p}<0.01$, and ${ }^{* * *} \mathrm{p}<0.001$ compared with the control group.
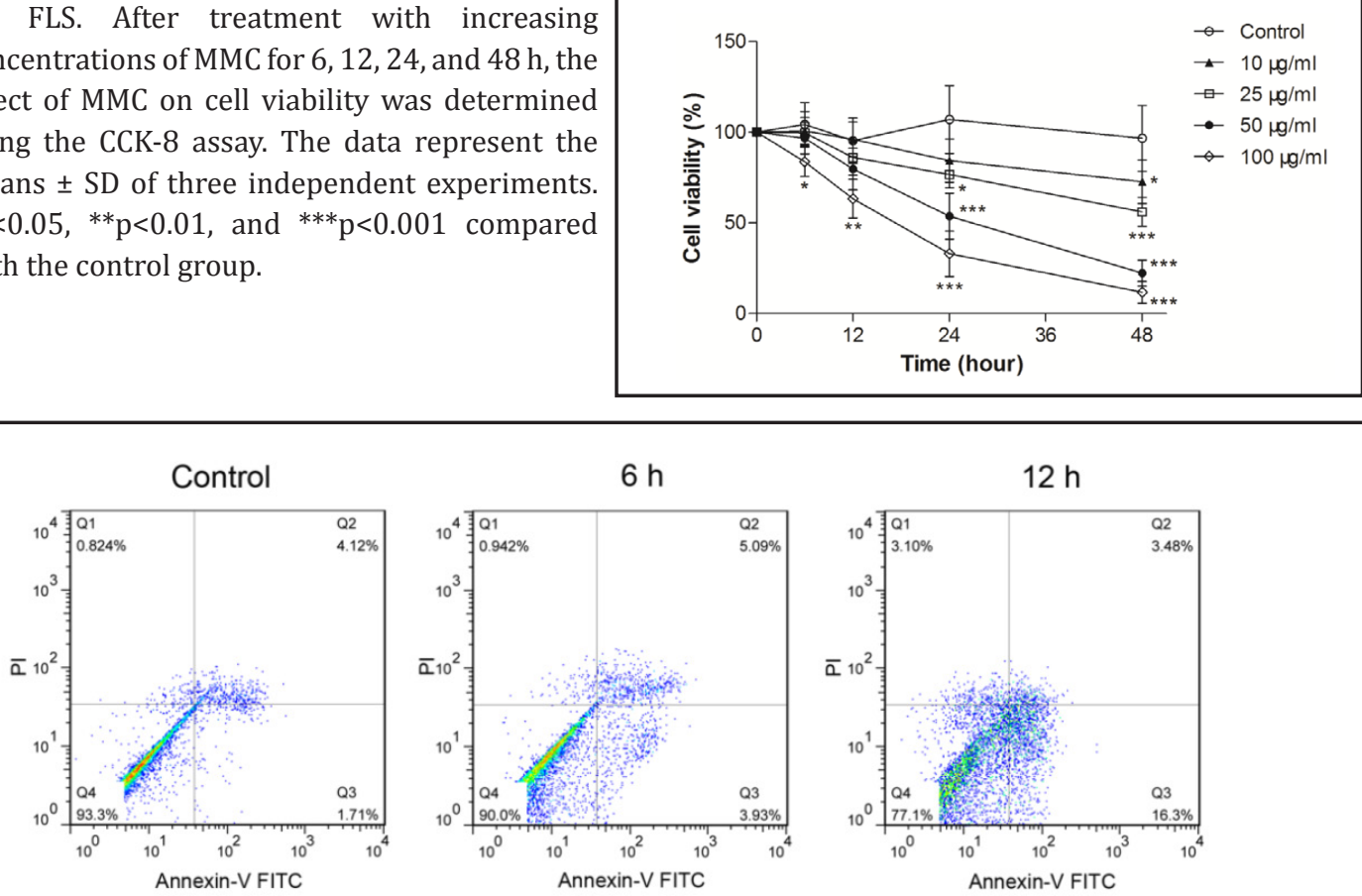

$24 \mathrm{~h}$

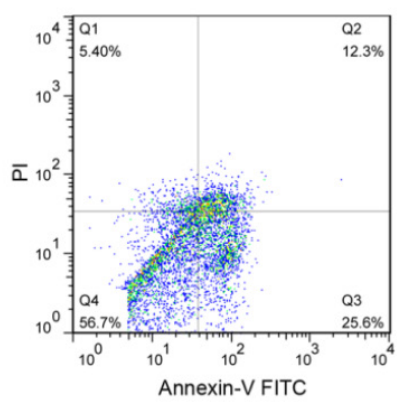

$48 \mathrm{~h}$
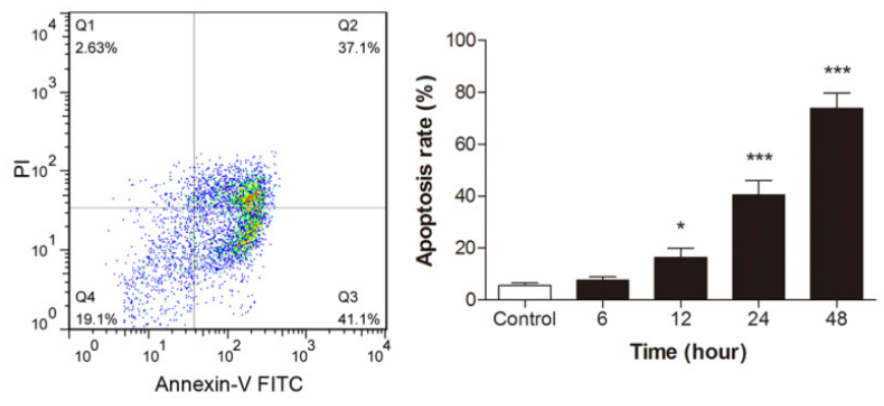

Fig. 2. MMC induces the apoptosis of RA FLS. Cells were treated with $50 \mu \mathrm{g} / \mathrm{ml}$ MMC for different durations $(6,12,24$, or $48 \mathrm{~h})$. The cell apoptosis rates were analysed via flow cytometry using the Annexin V-FITC/ PI double staining method. (A) Representative flow cytometric plots. Q1 represents necrotic cells; Q2 represents late apoptotic cells; Q3 indicates early apoptotic cells; and Q4 indicates living cells. (B) Graphic representations of the apoptotic rate of each group. The data represent the means \pm SD of three independent experiments. ${ }^{*} \mathrm{p}<0.05$ and ${ }^{* * *} \mathrm{p}<0.001$ compared with the control group.

control treatment $(2.33 \% \pm 1.25 \%)$. After treatment with MMC, the percentages of TUNELpositive cells at $6,12,24$, and 48 hours were $6.33 \% \pm 2.05 \%, 21 \% \pm 3.74 \%, 44.67 \% \pm 6.24 \%$, and $66.67 \% \pm 5.44 \%$, respectively. Taken together, these flow cytometry and TUNEL staining data indicate that MMC significantly induces apoptosis in RA FLS.

\section{MMC induces the production of intracellular ROS}

MMC-induced intracellular ROS production was detected using the fluorogenic probe DCFH-DA via flow cytometry. After exposure to MMC for the indicated periods, the levels of intracellular ROS were significantly increased within $24 \mathrm{~h}$ compared with the control treatment. The maximal increase in the ROS levels was achieved after $3 \mathrm{~h}$ of incubation (Fig. 4). These data reveal that MMC induced the production of intracellular ROS, even at $1 \mathrm{~h}$, implying that these cells were subjected to oxidative stress. 


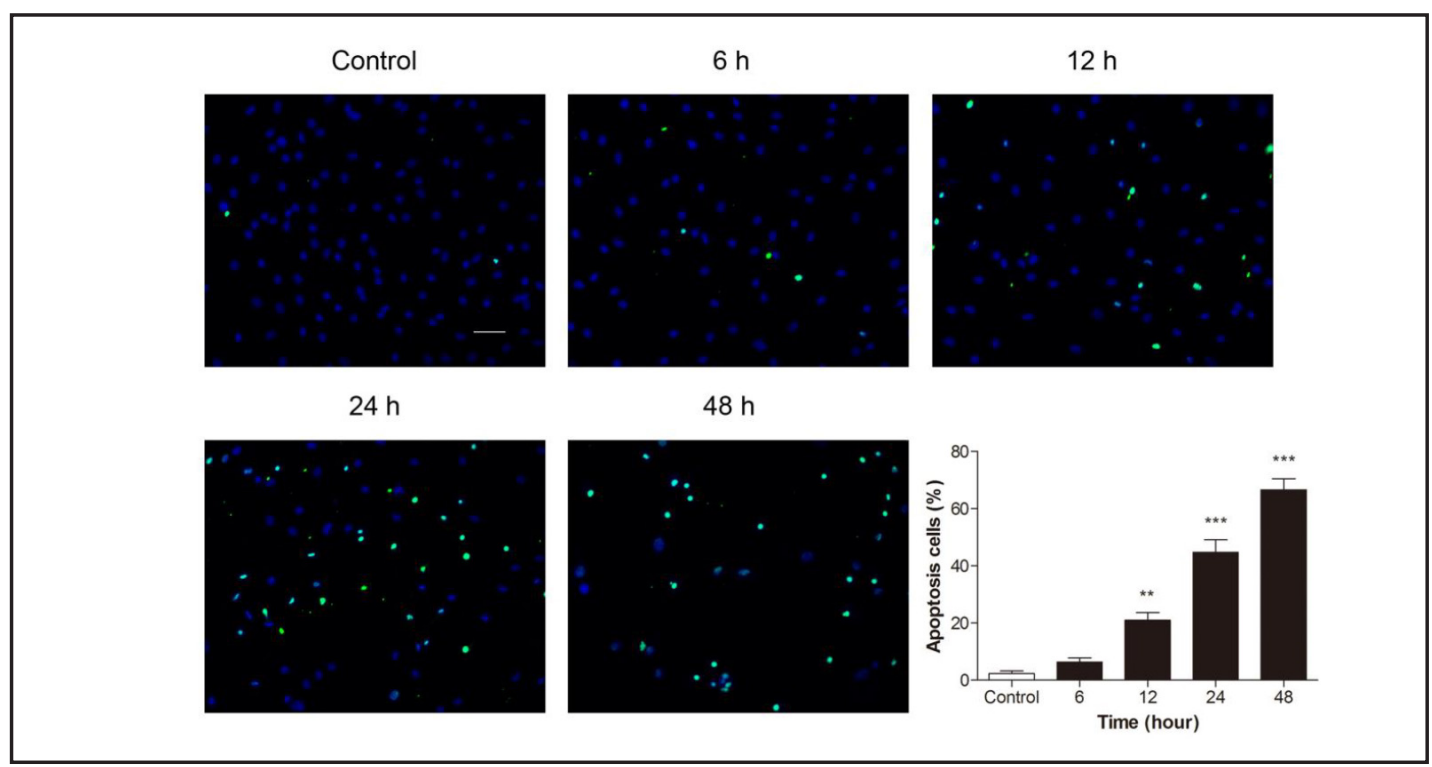

Fig. 3. The MMC-induced apoptosis of RA FLS as measured by TUNEL staining. FLS were exposed to $50 \mu \mathrm{g} /$ $\mathrm{ml} \mathrm{MMC} \mathrm{for} \mathrm{6,} \mathrm{12,} \mathrm{24,} \mathrm{or} 48 \mathrm{~h}$. The images were captured under a fluorescence microscope. The nuclei are shown in blue, and the TUNEL-positive cells are shown in green. The histogram shows the percentage of TUNEL-positive cells. The data represent the means \pm SD of three independent experiments. ${ }^{* *} \mathrm{p}<0.01$ and $* * * \mathrm{p}<0.001$ compared with the control group. Scale bar $=100 \mu \mathrm{m}$.

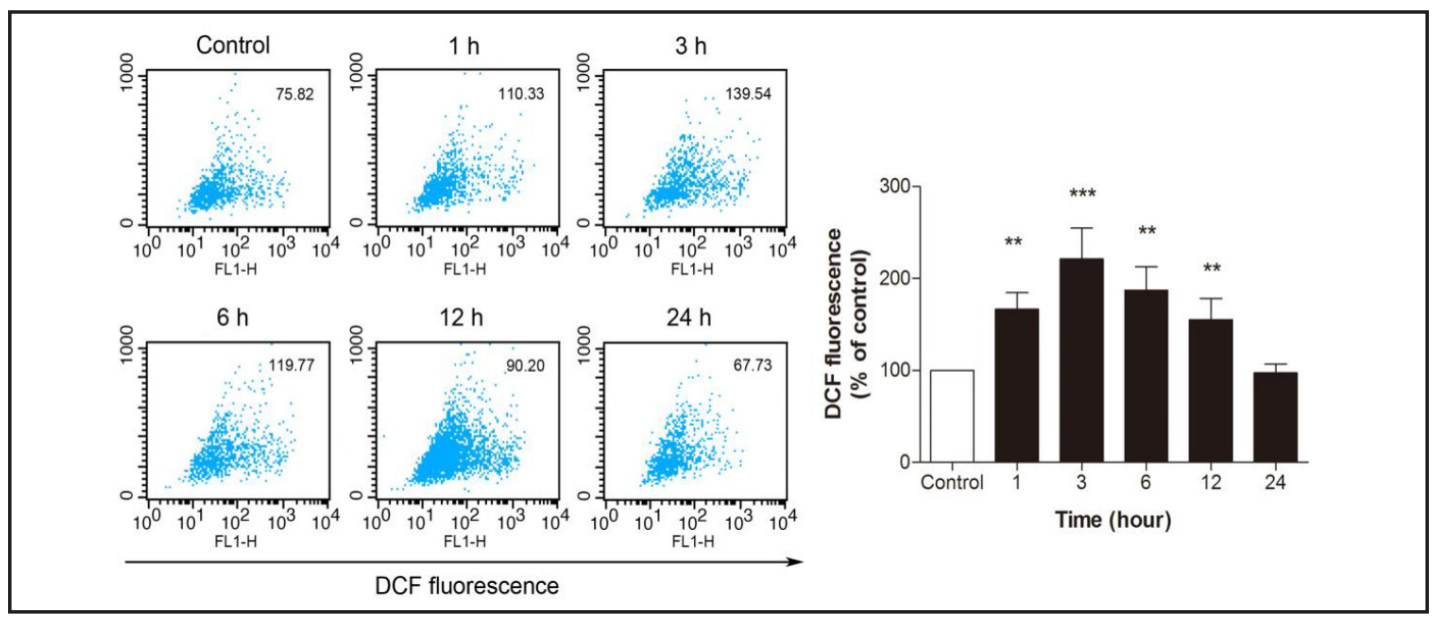

Fig. 4. Effect of MMC on intracellular ROS generation in cultured RAFLS. (A) FLS were treated with $50 \mu \mathrm{g} / \mathrm{ml}$ MMC for $1,3,6,12$, or $24 \mathrm{~h}$. The intracellular ROS levels were determined using the fluorogenic probe DCFHDA via flow cytometry. (B) The relative intensity of DCF fluorescence was expressed as a percentage of the DCF fluorescence in the control group. The values are presented as the means \pm SD of three independent experiments. ${ }^{* *} \mathrm{p}<0.01$ and ${ }^{* * *} \mathrm{p}<0.001$ compared with the control group.

$M M C$ induces the loss of $\triangle \Psi m$ and the release of mitochondrial cytochrome $c$

To investigate whether MMC-induced apoptosis is associated with mitochondrial dysfunction, the integrity of $\Delta \Psi \mathrm{m}$ was assessed using JC-1 fluorescence staining and visualised via fluorescence microscopy. As shown in Figure 5, the red fluorescence gradually decreased and the green fluorescence correspondingly increased following the MMC treatment, indicating the disruption of $\Delta \Psi \mathrm{m}$ and mitochondrial damage. Loss of the $\Delta \Psi \mathrm{m}$ initiates the release of cytochrome $\mathrm{c}$ into the cytosol, which subsequently activates a caspase cascade that results in apoptosis. Thus, we examined the release of cytochrome $c$ via Western blot analysis. As shown in Figure 6A, MMC treatment caused a time-dependent decrease in 
Yan et al.: Mitomycin C Induces Apoptosis in Rheumatoid Arthritis Fibroblast-Like Synoviocytes

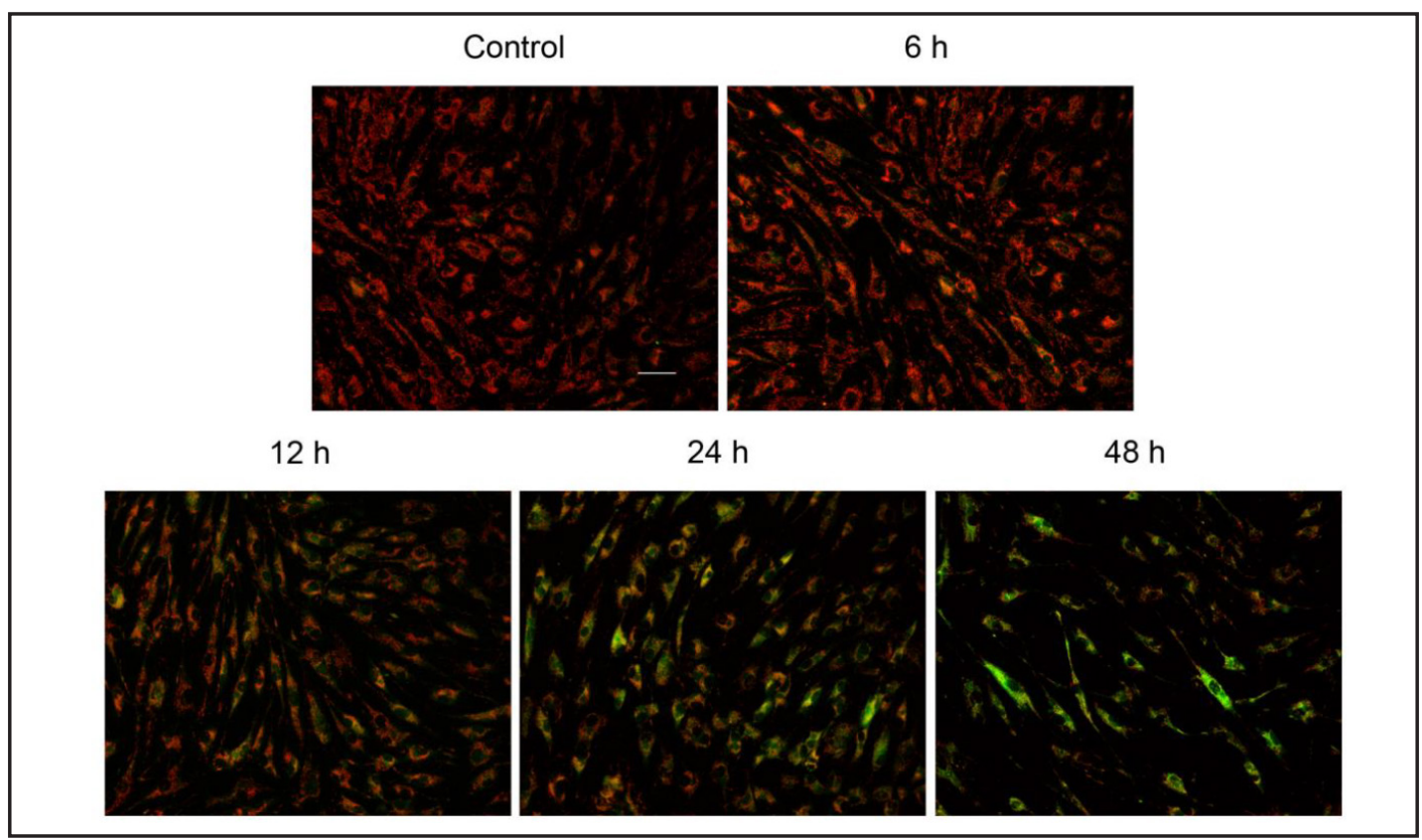

Fig. 5. MMC induces mitochondrial dysfunction in RA FLS. Cells were exposed to $50 \mu \mathrm{g} / \mathrm{ml} \mathrm{MMC}$ for 6,12 , 24 , or $48 \mathrm{~h}$, and the mitochondrial membrane potential was monitored by staining with the fluorescent dye JC-1. Red fluorescence represents the mitochondrial aggregated form of JC-1 due to a high $\Delta \Psi \mathrm{m}$, whereas green fluorescence indicates the monomeric form of JC-1 due to a low $\Delta \Psi \mathrm{m}$. Scale bar $=100 \mu \mathrm{m}$.

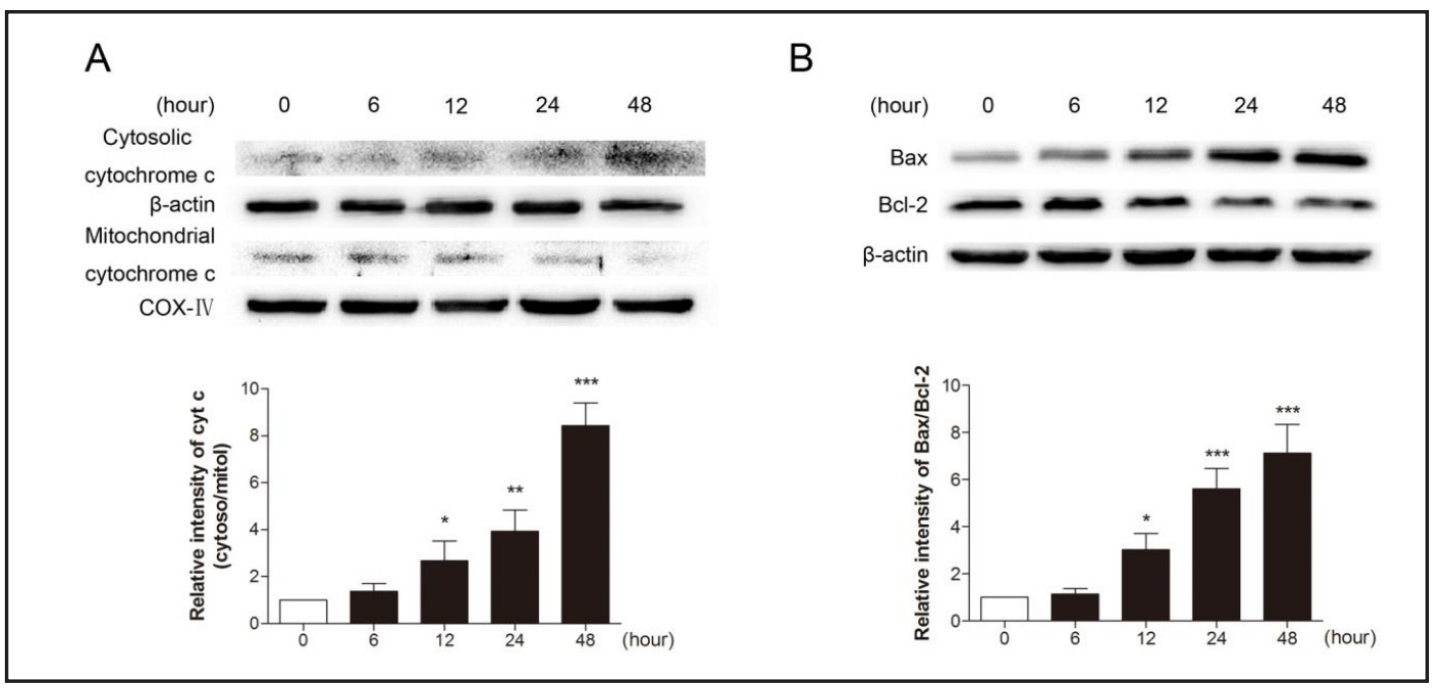

Fig. 6. Effect of MMC on the expression of apoptosis-related proteins as determined via Western blot analysis. After exposure to $50 \mu \mathrm{g} / \mathrm{ml} \mathrm{MMC}$ for $6,12,24$, or $48 \mathrm{~h}$, the protein expression levels of Bax, Bcl-2, and cytochrome $\mathrm{c}$ were determined via Western blot analysis. The expression levels of $\beta$-actin and COX-IV were used as loading controls. The values are presented as the means \pm SD of three independent experiments. ${ }^{*} \mathrm{p}<0.05,{ }^{* *} \mathrm{p}<0.01$ and ${ }^{* * *} \mathrm{p}<0.001$ compared with the control group.

the level of cytochrome $\mathrm{c}$ in the mitochondria and a corresponding increase in the cytosol, indicating its release from the mitochondria into the cytosol. Taken together, these findings suggest that mitochondrial dysfunction is likely involved in the MMC-induced apoptosis of RA FLS. 


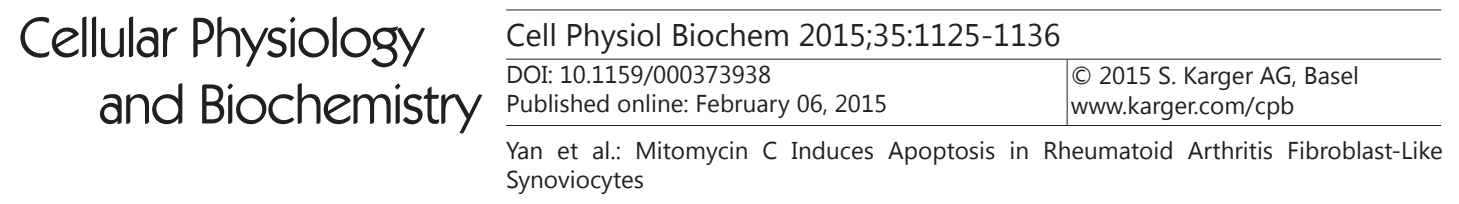

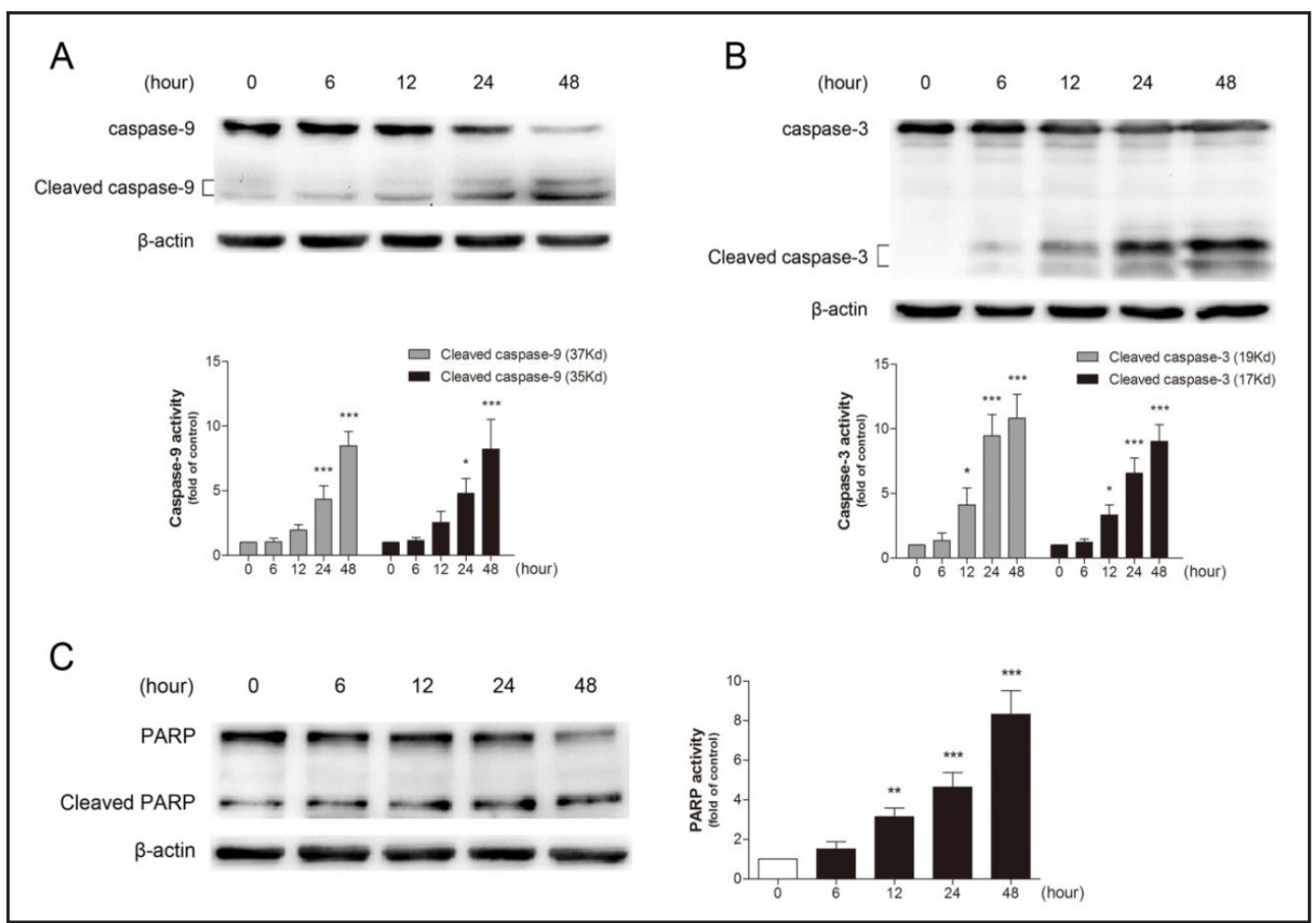

Fig. 7. MMC induces the activation of caspases and the cleavage of PARP in cultured RA FLS. Cells were treated with $50 \mu \mathrm{g} / \mathrm{ml} \mathrm{MMC}$ for the indicated periods. The protein expression levels of cleaved caspase-9, cleaved caspase-3 and cleaved PARP were determined via Western blot analysis. Quantitative analysis of cleaved caspase-9, cleaved caspase-3 and cleaved PARP were conducted. The values are presented as the means \pm SD of three independent experiments. ${ }^{*} \mathrm{p}<0.05,{ }^{* *} \mathrm{p}<0.01$ and ${ }^{* * *} \mathrm{p}<0.001$ compared with the control group.

\section{MMC affects the expression of apoptosis-related proteins in RA FLS}

Next, we examined the effect of MMC on the expression of Bcl-2 family proteins, which play an important role in the regulation of mitochondrial permeability. Western blot analysis revealed that MMC treatment increased the level of Bax and decreased the level of Bcl-2 in a time-dependent manner. Therefore, the ratio of Bax to Bcl-2 was increased (Fig. 6B). The caspase family is believed to play a central role in mediating various apoptotic responses. To confirm the induction of the apoptotic pathway, we examined the activation of caspase-9, caspase-3, and PARP. As shown in Figure 7, MMC induced a significant increase in cleaved fragments of caspase- 9 and caspase-3. PARP, which is a substrate of caspase- 3 , was also cleaved in response to MMC. These findings suggest that MMC induced apoptosis of RA FLS via the mitochondrial-mediated apoptotic pathway.

\section{Discussion}

MMC is an alkylating agent that displays potent anti-tumour activity. MMC impairs DNA replication and prevents protein synthesis, suppressing the proliferation of fibroblasts and epithelial cells and leading to the decreased development of granulation tissue and reduced scar formation, thereby diminishing the negative impacts of fibroblast proliferation [28-30]. Due to the recent increase in relevant studies and clinical trials, MMC has been successfully applied to decrease scar formation during postoperative wound healing in the fields of ophthalmology and spinal surgery [14, 31, 32]. Because FLS are homologous to fibroblasts, 
the primary objective of this experimental study was to investigate the effect of MMC on the apoptosis of FLS derived from RA patients and the mechanism underlying MMC-induced apoptosis.

Previous studies have confirmed the effectiveness of MMC in promoting antiproliferation and apoptotic signalling in fibroblasts [11]. In this study, we detected an influence of MMC on human RA FLS. The CCK-8 assay results showed that MMC effectively inhibited the proliferation of FLS in a dose- and time-dependent manner compared with the control treatment. In addition, MMC exposure caused an increase in the percentage of Annexin V-positive and TUNEL-positive cells. These results demonstrate that MMC inhibited the proliferation of human RA FLS and induced the apoptosis of these cells. In previous in vitro studies, fibroblasts are usually exposed to MMC at a high dose for short durations $[13,33]$. However, a relatively low concentration of MMC treatment for longer periods can also be found [34, 35]. Besides, RA FLS act like tumour cells and exhibit resistance to apoptosis compared with normal fibroblasts [5-7]. Based on these and the CCK-8 assay results, RA FLS were treated with MMC $(50 \mu \mathrm{g} / \mathrm{ml})$ for long periods in the present study.

Apoptosis is an ordered and orchestrated cellular suicide process that occurs under physiological and pathological conditions [36]. Oxidative stress is considered to be important for the promotion of apoptosis in response to a variety of apoptotic stimuli. ROS play essential roles in the oxidative stress response. Cells constitutively generate these molecules, which play important roles in redox balance and physiologic cell function. However, excessive ROS production can directly lead to mitochondrial damage and dysfunction, followed by a series of mitochondria-associated events, including apoptosis [17, 37, 38]. In our previous study, we found that MMC induces the apoptosis of epidural scar fibroblasts by elevating the production of intracellular ROS [13]. Though using different tissue types, common mechanisms may be shared. In agreement with these previous results, our current findings showed that MMC significantly increased the production of intracellular ROS in RA FLS, and the ROS levels peaked after $3 \mathrm{~h}$ of incubation. Therefore, excessive ROS generation is likely involved in MMC-induced apoptotic cell death in RA FLS.

It is well known that apoptosis occurs via two primary pathways: the extrinsic pathway, which is associated with cell death receptors and their ligands on the cellular surface, and the intrinsic pathway, which is dependent on mitochondria. The latter has been considered to be the predominant apoptosis-inducing pathway [16, 39]. Previous studies have demonstrated that mitochondrial dysfunction causes the collapse of $\Delta \Psi \mathrm{m}$, which results in mitochondrial permeability transition pore (mPTP) opening, enabling to the release of cytochrome $\mathrm{c}$ from the mitochondria into the cytosol $[40,41]$. The present study demonstrated that MMC exposure caused a loss of $\Delta \Psi \mathrm{m}$ in FLS and obvious clear translocation of cytochrome c from the mitochondria to the cytosol after MMC treatment. The level of cytochrome c decreased in the mitochondria and correspondingly increased in the cytosol. These data indicate that MMC caused mitochondrial damage to RA FLS.

The mitochondria-dependent apoptotic pathway is regulated by the Bcl-2 family of proteins, including Bax and Bcl-2 [25, 42]. Bax, which is a pro-apoptotic member of the Bcl-2 family, promotes the opening of the MPTP, causing the release of cytochrome c, whereas Bcl2 , which is an anti-apoptotic member of the Bcl-2 family, inhibits the formation of the MPTP, blocking cytochrome c release [43]. An increase in the Bax/Bcl-2 ratio has been demonstrated to promote apoptosis by directly activating the mitochondrial apoptotic pathway [44]. As demonstrated in the present study, the expression of Bcl-2 decreased, while that of Bax increased, resulting in an elevation in the Bax/Bcl-2 ratio, suggesting that MMC promoted the apoptosis of RA FLS via the mitochondrial-dependent apoptotic pathway.

Once released into the cytosol, cytochrome c triggers the activation of caspase-9. Subsequently, this initiator caspase activates downstream caspase-3, which is a critical executioner of apoptosis. Following caspase activation, an increasing number of cellular substrates, including the DNA repair protein PARP, are degraded or cleaved, resulting in cell death $[19,20,45]$. Multiple studies have shown that MMC causes to a notable induction of apoptosis via the mitochondrial-dependent apoptotic pathway $[46,47]$. Our findings are

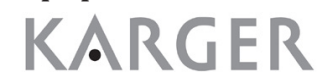


Yan et al.: Mitomycin C Induces Apoptosis in Rheumatoid Arthritis Fibroblast-Like Synoviocytes

consistent with these results, which showed that MMC significantly induced the activation of caspases- 9 and caspase-3. Further investigation revealed a time-dependent increase in PARP cleavage in the MMC-treated cells. Our data suggest that the caspase-dependent mitochondrial signalling pathway is involved in the mechanism underlying the MMC-induced apoptosis of RA FLS.

In conclusion, our study is the first report of the effective inhibition of FLS proliferation using MMC in a dose- and time-dependent manner, causing apoptotic cell death via excessive ROS generation and the mitochondrial-dependent pathway. These findings suggest that MMC may exert beneficial effects by postponing the process of joint destruction and relieving the pain experienced by RA patients.

\section{Disclosure Statement}

The authors declare no conflicts of interest.

\section{Acknowledgments}

This work was supported by grants from the National Natural Science Foundation of China (Grants \#81201374, \#81371968, and \#81171694) and a project funded by the Priority Academic Program Development of Jiangsu Higher Education Institutions (JX10231801). The authors thank Fang Wang for her helpful advice and the assistance of the laboratory of Cardiology.

\section{References}

1 Bresnihan B, Tak PP, Emery P, Klareskog L, Breedveld F: Synovial biopsy in arthritis research: Five years of concerted european collaboration. Ann Rheum Dis 2000;59:506-511.

2 Huber LC, Distler O, Tarner I, Gay RE, Gay S, Pap T: Synovial fibroblasts: Key players in rheumatoid arthritis. Rheumatology (Oxford) 2006;45:669-675.

3 Scott DL, Wolfe F, Huizinga TW: Rheumatoid arthritis. Lancet 2010;376:1094-1108.

4 Mor A, Abramson SB, Pillinger MH: The fibroblast-like synovial cell in rheumatoid arthritis: A key player in inflammation and joint destruction. Clin Immunol 2005;115:118-128.

5 Bartok B, Firestein GS: Fibroblast-like synoviocytes: Key effector cells in rheumatoid arthritis. Immunol Rev 2010;233:233-255.

6 Lefevre S, Knedla A, Tennie C, Kampmann A, Wunrau C, Dinser R, Korb A, Schnaker EM, Tarner IH, Robbins PD, Evans CH, Sturz H, Steinmeyer J, Gay S, Scholmerich J, Pap T, Muller-Ladner U, Neumann E: Synovial fibroblasts spread rheumatoid arthritis to unaffected joints. Nat Med 2009;15:1414-1420.

7 Baier A, Meineckel I, Gay S, Pap T: Apoptosis in rheumatoid arthritis. Curr Opin Rheumatol 2003;15:274279.

8 Bai S, Liu H, Chen KH, Eksarko P, Perlman H, Moore TL, Pope RM: Nf-kappab-regulated expression of cellular flip protects rheumatoid arthritis synovial fibroblasts from tumor necrosis factor alpha-mediated apoptosis. Arthritis Rheum 2004;50:3844-3855.

9 Schedel J, Gay RE, Kuenzler P, Seemayer C, Simmen B, Michel BA, Gay S: Flice-inhibitory protein expression in synovial fibroblasts and at sites of cartilage and bone erosion in rheumatoid arthritis. Arthritis Rheum 2002;46:1512-1518.

10 Sartorelli AC: The role of mitomycin antibiotics in the chemotherapy of solid tumors. Biochem Pharmacol 1986;35:67-69. 


\section{Cellular Physiology $\quad$ Cell Physiol Biochem 2015;35:1125-1136 and BiOchemistry \begin{tabular}{l|l} 
DoI: 10.1159/000373938 & $\begin{array}{l}\text { C 2015 S. Karger AG, Basel } \\
\text { www.karger.com/cpb }\end{array}$ \\
\hline
\end{tabular} \\ Yan et al.: Mitomycin C Induces Apoptosis in Rheumatoid Arthritis Fibroblast-Like Synoviocytes}

11 Seong GJ, Park C, Kim CY, Hong YJ, So HS, Kim SD, Park R: Mitomycin-c induces the apoptosis of human tenon's capsule fibroblast by activation of c-jun n-terminal kinase 1 and caspase- 3 protease. Invest Ophthalmol Vis Sci 2005;46:3545-3552.

12 Chou SF, Chang SW, Chuang JL: Mitomycin c upregulates il-8 and mcp-1 chemokine expression via mitogenactivated protein kinases in corneal fibroblasts. Invest Ophthalmol Vis Sci 2007;48:2009-2016.

13 Shi K, Wang D, Cao X, Ge Y: Endoplasmic reticulum stress signaling is involved in mitomycin c (mmc)induced apoptosis in human fibroblasts via perk pathway. PLoS One 2013;8:e59330.

14 Sun Y, Wang LX, Wang L, Sun SX, Cao XJ, Wang P, Feng L: A comparison of the effectiveness of mitomycin $\mathrm{c}$ and 5-fluorouracil in the prevention of peridural adhesion after laminectomy. J Neurosurg Spine 2007; 7:423-428.

15 Ashkenazi A, Dixit VM: Death receptors: Signaling and modulation. Science 1998;281:1305-1308.

16 Wang J, Yuan L, Xiao H, Xiao C, Wang Y, Liu X: Momordin ic induces hepg2 cell apoptosis through mapk and pi3k/akt-mediated mitochondrial pathways. Apoptosis 2013;18:751-765.

17 Cha Y, Park DW, Lee CH, Baek SH, Kim SY, Kim JR, Kim JH: Arsenic trioxide induces apoptosis in human colorectal adenocarcinoma ht-29 cells through ros. Cancer Res Treat 2006;38:54-60.

18 Scorrano L, Korsmeyer SJ: Mechanisms of cytochrome c release by proapoptotic bcl-2 family members. Biochem Biophys Res Commun 2003;304:437-444.

19 Kim HE, Du F, Fang M, Wang X: Formation of apoptosome is initiated by cytochrome c-induced datp hydrolysis and subsequent nucleotide exchange on apaf-1. Proc Natl Acad Sci U S A 2005;102:1754517550.

20 Boulares AH, Zoltoski AJ, Sherif ZA, Yakovlev A, Smulson ME: Roles of DNA fragmentation factor and poly(adp-ribose) polymerase-1 in sensitization of fibroblasts to tumor necrosis factor-induced apoptosis. Biochem Biophys Res Commun 2002;290:796-801.

-21 Arnett FC, Edworthy SM, Bloch DA, McShane DJ, Fries JF, Cooper NS, Healey LA, Kaplan SR, Liang MH, Luthra HS, et al.: The american rheumatism association 1987 revised criteria for the classification of rheumatoid arthritis. Arthritis Rheum 1988;31:315-324.

-22 Hempel SL, Buettner GR, O'Malley YQ, Wessels DA, Flaherty DM: Dihydrofluorescein diacetate is superior for detecting intracellular oxidants: Comparison with 2',7'-dichlorodihydrofluorescein diacetate, 5(and 6)-carboxy-2',7'-dichlorodihydrofluorescein diacetate, and dihydrorhodamine 123. Free Radic Biol Med 1999;27:146-159.

23 de Grey AD: Free radicals in aging: Causal complexity and its biomedical implications. Free Radic Res 2006;40:1244-1249.

24 Reers M, Smith TW, Chen LB: J-aggregate formation of a carbocyanine as a quantitative fluorescent indicator of membrane potential. Biochemistry 1991;30:4480-4486.

25 Kong D, Zheng T, Zhang M, Wang D, Du S, Li X, Fang J, Cao X: Static mechanical stress induces apoptosis in rat endplate chondrocytes through mapk and mitochondria-dependent caspase activation signaling pathways. PLoS One 2013;8:e69403.

-26 Huang HC, Shi GY, Jiang SJ, Shi CS, Wu CM, Yang HY, Wu HL: Thrombomodulin-mediated cell adhesion: Involvement of its lectin-like domain. J Biol Chem 2003;278:46750-46759.

-27 Tseng CP, Huang CL, Huang CH, Cheng JC, Stern A, Tseng CH, Chiu DT: Disabled-2 small interfering rna modulates cellular adhesive function and mapk activity during megakaryocytic differentiation of k562 cells. FEBS Lett 2003;541:21-27.

28 Wilson SE, Mohan RR, Mohan RR, Ambrosio R, Jr., Hong J, Lee J: The corneal wound healing response: Cytokine-mediated interaction of the epithelium, stroma, and inflammatory cells. Prog Retin Eye Res 2001;20:625-637.

29 Galm U, Hager MH, Van Lanen SG, Ju J, Thorson JS, Shen B: Antitumor antibiotics: Bleomycin, enediynes, and mitomycin. Chem Rev 2005;105:739-758.

30 Hata T, Hoshi T, Kanamori K, Matsumae A, Sano Y, Shima T, Sugawara R: Mitomycin, a new antibiotic from streptomyces. I. J Antibiot (Tokyo) 1956;9:141-146.

31 Buss DG, Sharma A, Giuliano EA, Mohan RR: Efficacy and safety of mitomycin c as an agent to treat corneal scarring in horses using an in vitro model. Vet Ophthalmol 2010;13:211-218.

-32 Lee JY, Stenzel W, Ebel H, Wedekind C, Ernestus RI, Klug N: Mitomycin c in preventing spinal epidural fibrosis in a laminectomy model in rats. J Neurosurg 2004;100:52-55. 


\section{Cellular Physiology $\quad$ Cell Physiol Biochem 2015;35:1125-1136 and Biochemistry \\ Yan et al.: Mitomycin C Induces Apoptosis in Rheumatoid Arthritis Fibroblast-Like Synoviocytes}

33 Li NY, Chen F, Dikkers FG, Thibeault SL: Dose-dependent effect of mitomycin c on human vocal fold fibroblasts. Head Neck 2014;36:401-410.

34 Kim TI, Choi SI, Lee HK, Cho YJ, Kim EK: Mitomycin c induces apoptosis in cultured corneal fibroblasts derived from type ii granular corneal dystrophy corneas. Mol Vis 2008;14:1222-1228.

-35 Cai X, Yang X, Cai J, Wu S, Chen Q: Atomic force microscope-related study membrane-associated cytotoxicity in human pterygium fibroblasts induced by mitomycin c. J Phys Chem B 2010;114:3833-3839.

-36 Xue X, Yu JL, Sun DQ Kong F, Qu XJ, Zou W, Wu J, Wang RM: Curcumin induces apoptosis in sgc-7901 gastric adenocarcinoma cells via regulation of mitochondrial signaling pathways. Asian Pac J Cancer Prev 2014;15:3987-3992.

-37 Cui ZG, Piao JL, Kondo T, Ogawa R, Tsuneyama K, Zhao QL, Feril LB, Jr., Inadera H: Molecular mechanisms of hyperthermia-induced apoptosis enhanced by docosahexaenoic acid: Implication for cancer therapy. Chem Biol Interact 2014;215:46-53.

-38 Ryter SW, Kim HP, Hoetzel A, Park JW, Nakahira K, Wang X, Choi AM: Mechanisms of cell death in oxidative stress. Antioxid Redox Signal 2007;9:49-89.

-39 Fulda S, Debatin KM: Extrinsic versus intrinsic apoptosis pathways in anticancer chemotherapy. Oncogene 2006;25:4798-4811.

40 Chan SH, Leu WJ, Hsu LC, Chang HS, Hwang TL, Chen IS, Chen CS, Guh JH: Reevesioside f induces potent and efficient anti-proliferative and apoptotic activities through na(+)/k(+)-atpase alpha3 subunit-involved mitochondrial stress and amplification of caspase cascades. Biochem Pharmacol 2013;86:1564-1575.

41 Wu W, Zhou X, Liu P, Fei W, Li L, Yun H: Isoflurane reduces hypoxia/reoxygenation-induced apoptosis and mitochondrial permeability transition in rat primary cultured cardiocytes. BMC Anesthesiol 2014;14:17.

42 Green DR, Kroemer G: The pathophysiology of mitochondrial cell death. Science 2004;305:626-629.

43 Wang Y, Li X, Wang X, Lau W, Wang Y, Xing Y, Zhang X, Ma X, Gao F: Ginsenoside rd attenuates myocardial ischemia/reperfusion injury via akt/gsk-3beta signaling and inhibition of the mitochondria-dependent apoptotic pathway. PLoS One 2013;8:e70956.

44 Brunelle JK, Letai A: Control of mitochondrial apoptosis by the bcl-2 family. J Cell Sci 2009;122:437-441.

$\$ 45$ Singh N, Sarkar J, Sashidhara KV, Ali S, Sinha S: Anti-tumour activity of a novel coumarin-chalcone hybrid is mediated through intrinsic apoptotic pathway by inducing puma and altering bax/bcl-2 ratio. Apoptosis 2014;19:1017-1028.

46 Pirnia F, Schneider E, Betticher DC, Borner MM: Mitomycin c induces apoptosis and caspase-8 and -9 processing through a caspase-3 and fas-independent pathway. Cell Death Differ 2002;9:905-914.

47 Wu KY, Wang HZ, Hong SJ: Mechanism of mitomycin-induced apoptosis in cultured corneal endothelial cells. Mol Vis 2008;14:1705-1712. 